\title{
LA ARQUITECTURA DE LADRILLOS DEL SIGLO XIX: RACIONALIDAD Y MODERNIDAD
}

\author{
(19 ${ }^{\text {th }}$ CENTURY BRICK ARCHITECTURE: RATIONALITY AND MODERNITY)
}

Josep M. Adell Argilés, Dr. Arquitecto

Profesor Titular del Departamento de Construcción y Tecnología Arquitectónicas

Escuela T.S. de Arquitectura-Universidad Politécnica de Madrid.

ESPAÑA

Fecha de recepción: 23-VII-92

\section{RESUMEN}

El análisis de las obras de Arquitectura construidas con ladrillo en Europa, entre mediados del siglo XIX y principios del XX, demuestra que explotaban las posibilidades técnicas y formales del material, y seguian la corriente de racionalidad constructiva imperante en los inicios de la era industrial.

Estas obras revelan suficientes conexiones entre sí, para poderlas agrupar bajo la denominación común de "Arquitectura de Ladrillos del siglo XIX", por encima de matices estilísticos propios de cada región o país.

En el artículo se analizan aquellos valores más significativos de la Arquitectura de Ladrillos, que permiten entenderla como un paso hacia la modernidad.
SUMMARY

The analysis of brick architectural works in Europe between the middle of the $19^{\text {th }}$ century and the beginning of the $20^{\text {th }}$ century shows that they already exploted the tecnical and formal material possibilities and they followed the constructive rationality tendency preveailing in the beginnings of the industrial era.

These works reveal enough connections among themselves, so as to be able to assemble them under the common name of " $19^{\text {th }}$ Century Brick Architecture", a name beyond nuances of style characteristic of each region or country.

This article analyzes those most significant values of the Brick Architecture which allow it to be understood as a step towards modernity.
Durante las últimas décadas del siglo XIX, se realizó en Europa una interesante arquitectura que tenía como denominador común el ladrillo.

En España, los historiadores la denominaron con el nombre genérico de arquitectura "neo-mudéjar", asociándola con arquitecturas antiguas donde podía mostrarse el ladrillo a la vista. Con este término parecía que quedaban inmediatamente resueltos conceptos teóricos de carácter estilístico, formal, e incluso de datación.

Pero si se analiza esta arquitectura con más rigor, atendiendo también a los aspectos tecnológicos, constructi- vos y compositivos, nos daremos cuenta, de un modo casi inmediato, que los conceptos que encierra son mucho más amplios, quedándose corta dicha denominación, ya que se refiere sólo a un aspecto formal que caracterizó algunas de las obras significativas, como las construídas en Madrid, desde la Plaza de Toros de Rodríguez Ayuso y Álvarez Capra de 1874, ya derribada, hasta la Plaza Monumental de las Ventas en 1932. (fig. 1).

Si eludimos la parcialización que supone enfrentarse a la arquitectura separándola por estilos, podremos ver con claridad la identidad que caracteriza a una forma de edificar, que podemos llamar a partir de ahora sencillamente como ARQUITECTURA DE LADRILLOS DEL SIGLO XIX. 


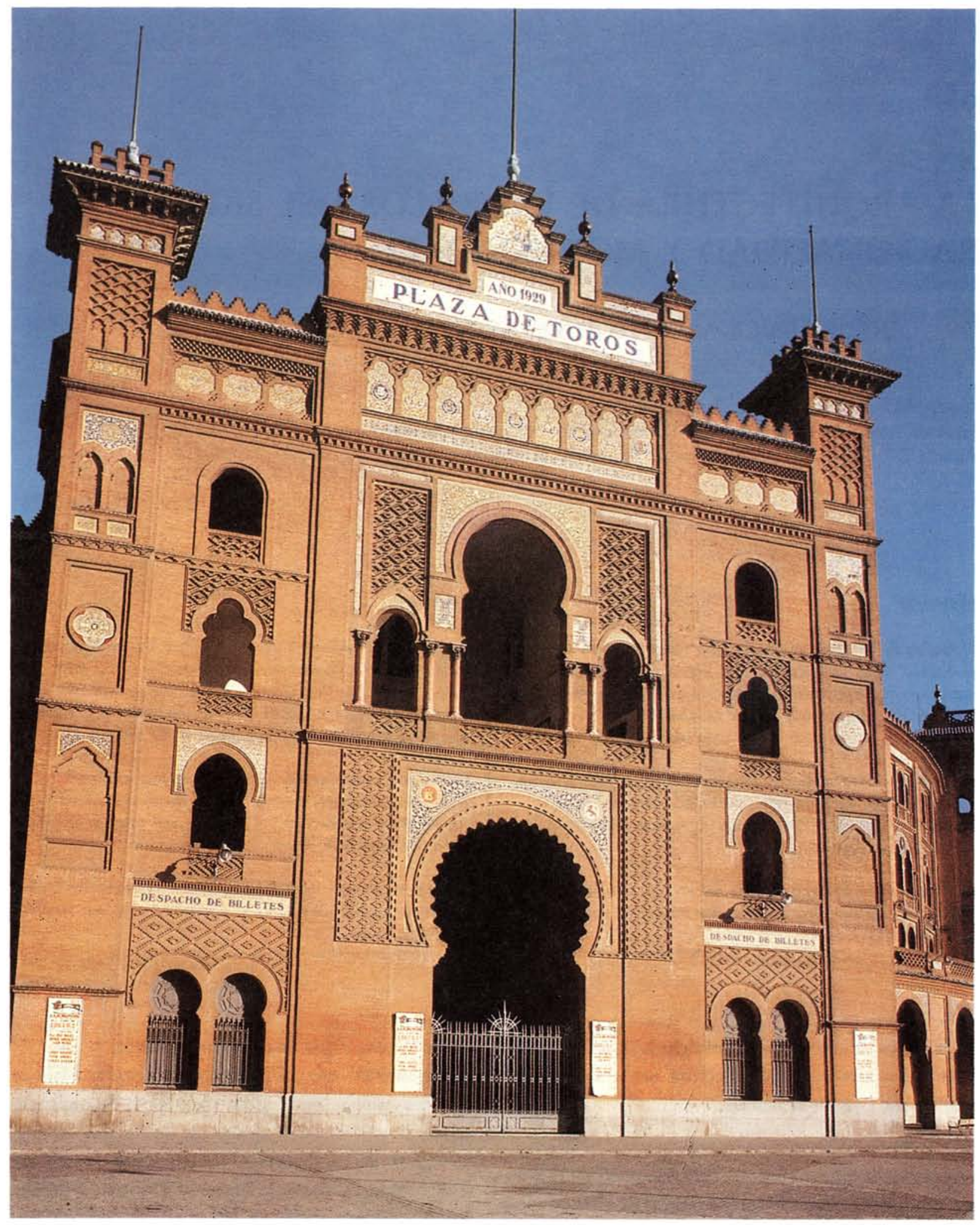

Fig. 1.-Plaza de Toros Monumental. Madrid. 1912-1932. J. Espelius y M. Muñoz Monasterio. 


\section{EL LADRILLO: ELEMENTO MODULAR}

Fijémonos en el transfondo del término "ladrillos" para poder adentrarnos en esta Arquitectura, definida en sí misma con la denominación del material con que está construída.

El ladrillo ha sido utilizado a lo largo de toda la historia, pero en el siglo XIX empieza a tener una importancia propia, porque resume en sí mismo todo un proceso de industrialización característico de la época.

La utilización de estas piezas cerámicas paralepipédicas, durante el XIX, connotan una serie de avances técnicos y formales, que llegarán a tener hasta un valor simbólico de progreso en la manera de utilizarse.

Se dan en este siglo los grandes avances tecnológicos de la Industria Ladrillera. Los hornos hormigueros se sustituyen por circulares y de túnel. Las amasadoras, galleteras, etc., aumentarán enormemente la productividad. El resultado será un elemento prefabricado con unas características físicas determinadas y controlables.

Si bien no todos los ladrillos van a ser exactamente iguales en medidas, comenzará un proceso de modulación, que poco a poco irá haciendo que se abandonen las antiguas proporciones, más o menos cuadradas, iniciándose una unificación de formas y tamaños hasta quedar establecida la proporción de "el largo igual al doble de el ancho".

Además aparecen nuevos tipos de piezas resultado directo de los sistemas de fabricación industrializada: ladrillos huecos, perforados o prensados, e incluso a finales de siglo los materiales prefabricados conglomerados empiezan a surgir como alternativa.

Por otra parte, es necesario que recordemos que es en esta época cuando las maneras tradicionales de pesar o medir van a ser sometidas a un proceso de unificación. Las sogas, las varas, los pies y los palmos..., de cada lugar, van a ir dejando paso al Sistema Métrico Decimal, como el sistema nuevo, único y universal de medidas.

El resultado de toda esta transformación fue que el "el ladrillo" pasó a considerarse como un "material nuevo" con el carácter de "pieza-módulo", que pasó a entenderse como el "elemento básico" de toda una "estructura" que permitía "racionalizar la composición de la arquitectura" en base a "principios constructivos".
Con este entendimiento nuevo del ladrillo se construía la arquitectura de la época, con estilos muy diversos, siempre que se quería apostar por una "opción de modernidad" con el uso de un "material tradicional", "evolucionado por la revolución industrial".

\section{RACIONALIDAD: DE LA TRABAZÓN AL APAREJO}

Para entender la evolución que se da en la organización constructiva de la fábrica, pasando de la trabazón al aparejo, veamos el siguiente caso concreto:

En las Ordenanzas de Madrid de 1857, recogidas por Fornés y Gurrea en su Arte de Edificar (2), que dice ser las mismas que regían en Valencia y Sevilla, se estipulaba por ley que los ladrillos, que debían utilizarse en obra, debían de tener un pie de largo, por una cuarta de ancho y dos dedos de grueso; medidas éstas dependientes de los submúltiplos de la Vara -en tres partes "pies", y en cuatro partes "cuartas"-, lo que daba una proporción de la tabla de la pieza, donde el largo no era el doble del ancho. En Castilla, la dimensión métrica de la vara era de $864 \mathrm{~cm}$.

Este tipo de pieza obligada por ordenanza impedía, por la proporción de su tabla de 3 a 4, alternar la disposición del ladrillo "a lo largo" y "a lo ancho" en la fábrica. Para una buena ejecución del muro era suficiente contemplar la trabazón, tanto por su frente como por su grueso, es decir, evitar la continuidad vertical de las juntas disponiendo los ladrillos de manera uniforme.

Sorprende enormemente que en el libro "Arte de Albañilería" de Juán de Villanueva, editado en Madrid en 1827 (Basado en el libro "Arte y uso de Arquitectura" de Fray Lorenzo de San Nicolás de 1667) (1) no existía la denominación de "aparejo" sino solamente la de "trabazón". Los gráficos que en él se muestran corroboran la utilización del ladrillo de proporciones indicado en la ordenanza, con el imposible juego entre sogas y tizones.

Se han encontrado ladrillos de un pie de largo por una cuarta de ancho, en restauraciones de edificios antiguos, que confirman lo expuesto.

La imposibilidad de jugar con piezas a lo largo y a lo ancho llevará a que, cuando se normalice el ladrillo, y la proporción pase a duplicar su largo en relación al ancho, el aparejo que se utilice en Madrid sea el aparejo a tizón, siguiendo utilizándose la misma manera tradicional de trabar (Fig. 2). 


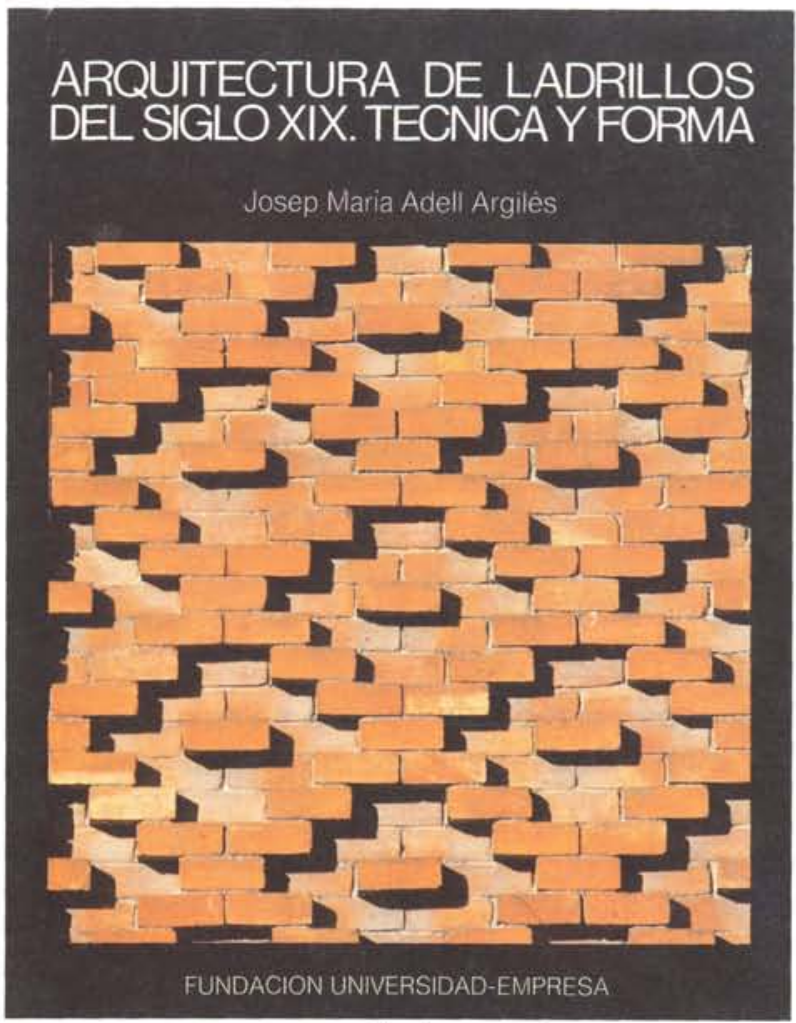

Fig. 2

Se puede comprobar cómo en Madrid no existía tradición de dejar las fábricas vistas, conociendo la Arquitectura anterior.

La arquitectura de épocas anteriores había utilizado el ladrillo como un material acumulativo, que tras un proceso de trabazón conformaría el muro. ¿Dónde está pues la diferencia? ¿Por qué en el siglo XIX se está dando prioridad al material, como rasgo definitorio de una arquitectura? Sencillamente porque en este caso el empleo del ladrillo se hace con tal racionalidad que da a esta arquitectura una estructura singular, tanto desde el punto de vista técnico como formal.

Durante todo el siglo XIX, y debido precisamente a que el ladrillo adquiere unas proporciones fijas, la trabazón como proceso constructivo deja paso al aparejo de una manera generalizada.

El "aparejo" constituye una técnica combinatoria, que hace que el proceso de adición sea sustituido por una serie de leyes lógicas que dan a los muros, construídos con ellas, unas características formales propias y resistentes precisas.

Es a finales del siglo XIX cuando se toma conciencia de que la denominación genérica de "aparejo" en el ladrillo, referida a la "adecuada disposición de los elementos en la fábrica", adquiere además en cada caso concreto un "valor específico", determinado por cada una de las diversas maneras posibles de disponer las piezas en la fábrica de forma regular, garantizando además la trabazón.

Esto hace que en toda Europa comiencen a aparecer libros donde se especifiquen algunas de estas leyes combinatorias que en sus orígenes se las denomina simplemente con números, como es el caso del libro francés: "La brique ordinaire au point de vue decoratif" (3) donde se dibujan los aparejos denominados: aparejo $1,2, \ldots 6$.

El hecho de comprobarse que en determinados lugares -países o regiones- es habitual organizar las fábricas articulando los ladrillos de una manera constante, lleva a asociar la denominación del "aparejo" con el "nombre del lugar". En este sentido se conocen el aparejo inglés, flamenco, holandés, belga, etc.

En Madrid, como se demuestra en la investigación publicada en el libro "Arquitectura de Ladrillos del siglo XIX. Técnica y Forma” (4), todos los edificios construídos en esta época disponian "a tizón" el ladrillo en la fábrica (por las razones ya expuestas). Tal circunstancia, sumada a motivos de carácter nacionalista, llevaron a establecer el sinónimo entre "aparejo a tizón" y "aparejo a la española" (5).

La Arquitectura de Ladrillos madrileña, que expone al exterior "las testas" de los ladrillos y el máximo de juntas, muestra el paramento lo más subdividido posible de acuerdo a la modulación de la pieza.

El aparejo "a tizón" permite conseguir mayor juego ornamental que el resultante de combinar sogas con tizones. Este hecho técnico, hace que la Arquitectura de Ladrillos "a la española", destaque por su riqueza formal frente a las demás Arquitecturas de Ladrillos de la época, construidas con otros aparejos.

$\mathrm{Si}$ analizamos el proceso combinatorio que permite la pieza prismática, desde un punto de vista geométrico y constructivo, nos daremos cuenta de que se hace casi infinito, siguiendo sencillas reglas de articulación del ladrillo (Fig. 3).

Además de las habituales maneras de colocar el ladrillo en la fábrica en posición horizontal y vertical, combinando el ancho y el largo, lo que da lugar a las denominaciones de: "a tizón", "a soga", "a sardinel”, o "sardinel de canto". Existe también la posibilidad de colocarlo en situación oblícua llamada "triscada". 
$H \mid L A D A$

DE

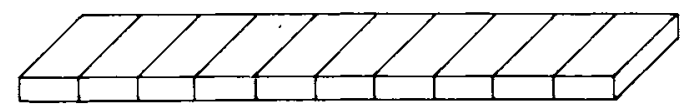

(A) HILADA

CORRIDA A TIZON

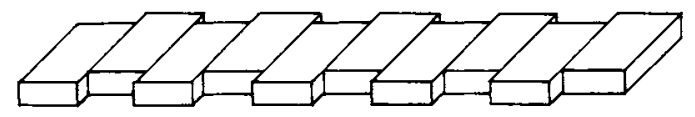

(B) HILADA DENTELLADA A TIZON

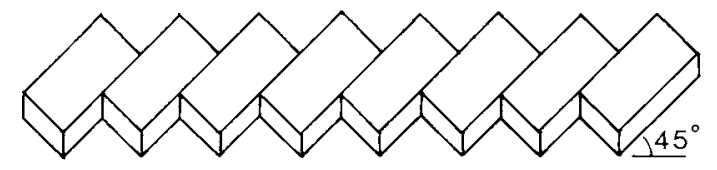

(C) HILADA A SERRta POR tABla
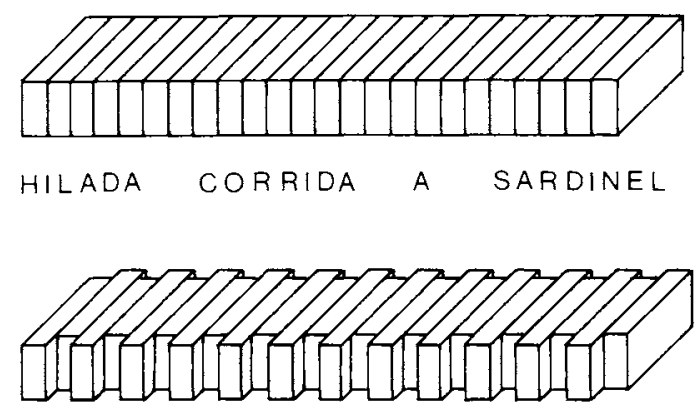

(E) HILADA DENTELLADA A SARDINEL

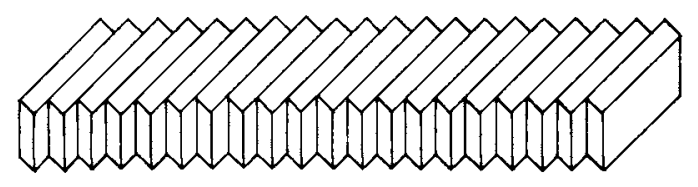

(F) HILADA ARPADA A SARDINEL

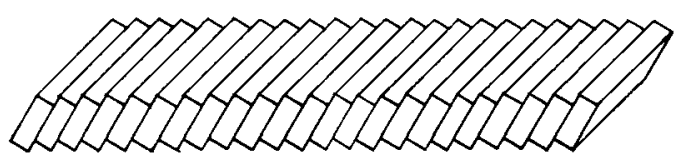

(G) HILADA TRISCADA A SARDINEL

(H) TRISCADA DENTELLADA A SARDINEL

(1) TRISCADA ARPADA A SARDINEL
$L A D R \quad L L O S$

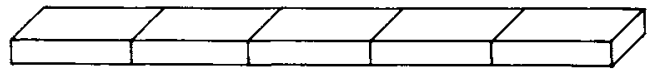

HILADA CORRIDA A SOGA (A)

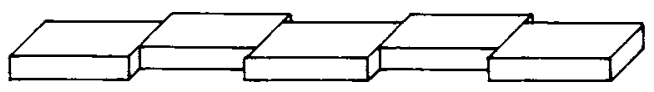

HILADA DENTELLADA A SOGA (B)

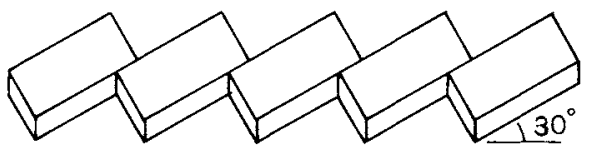

HILADA "A CORRIENTE"

(C)

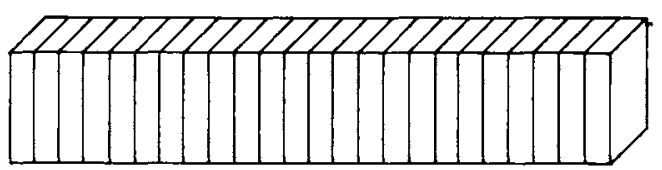

H. CORRIDA A SARDINEL DE CANTO (D)

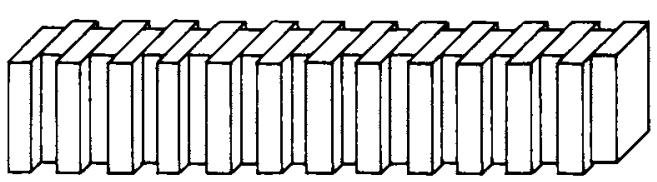

H. DENTE A SARDINEL DE CANTO E)

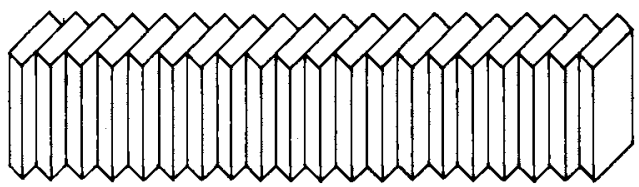

H. ARPADA A SARDINEL DE CANTO (F)

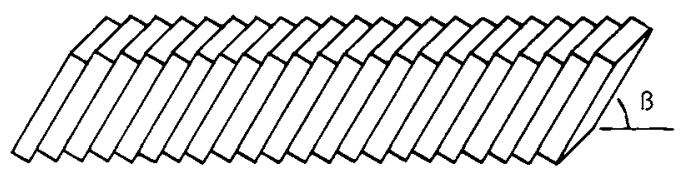

H. TRISCADA A SARDINEL DE CANTO (G)

TRIS DENTE A SARDINEL DE CANTO (H)

TRIS. ARPADA A SARDINEL DE CANTO (1)

Enrasada $(\cdot)$. Rehundida $(-)$ Resaltada(t) 
En todos esos casos, además, las hiladas de ladrillos pueden ser "corridas", "dentelladas" o "arpadas".

El aspecto plástico de la fábrica vista puede potenciarse jugando además: a "rehundir", "enrasar" o "resaltar" las hiladas respecto al haz del paramento, lo que añade atractivos matices de luz y sombra.

El aspecto cromático puede enfatizarse utilizando, en las disposiciones anteriores, ladrillos de distintos "colores".

\section{LA ARQUITECTURA DE LADRILLOS EUROPEA: UN CAMINO HACIA LA MODERNIDAD}

El resultado formal de estas combinaciones, de orden abstracto, conduce a una arquitectura que servirá para construir en Europa la denominada Arquitectura de Ladrillos del Siglo XIX y que incluirá edificios tan diferentes entre sí como la Plaza de Toros de Madrid, la Escuela de Arquitectura de Shinckel en Berlín, o el modelo de una Casa de Jardinero publicado por Chabat en "La brique et la terra cuita" -París 1880-89-, para que cualquier constructor la pudiera edificar (Fig. 4).

Había entre estos edificios diferencias ideológicas importantes: unos tomaron como modelo figurativo el gótico, otros el románico o el mudéjar, en suma modelos neomedievales.

Pero todos son el resultado de las corrientes intelectuales que se plantearon en el siglo XIX como una respuesta a los interrogantes de modernidad que se habían pronunciado en el XVIII y, lo que es más imporatante, un camino directo para entender la Arquitectura que se realizará en el siglo XX.

En realidad, esta Arquitectura de Ladrillos del XIX puede considerarse como una respuesta popular a la arquitectura culta clasicista. En ella, los maestros artesanos y los albañiles plasman su libertad, ajustándose a las sencillas leyes del aparejo, y conciben "su arquitectura" cargándola de valores morales y locales.

Se habla de su sinceridad constructiva:

"Dejad vuestras paredes lisas y desnudas, no las enyeséis con mentiras"... -escribe John Ruskin- (6).

Se le asocia de un modo literario incluso a teorías socialistas (William Morris), y refleja las tradiciones autóctonas de cualquier punto de Europa, en un momento en que los nacionalismos están teniendo tantísima fuerza.

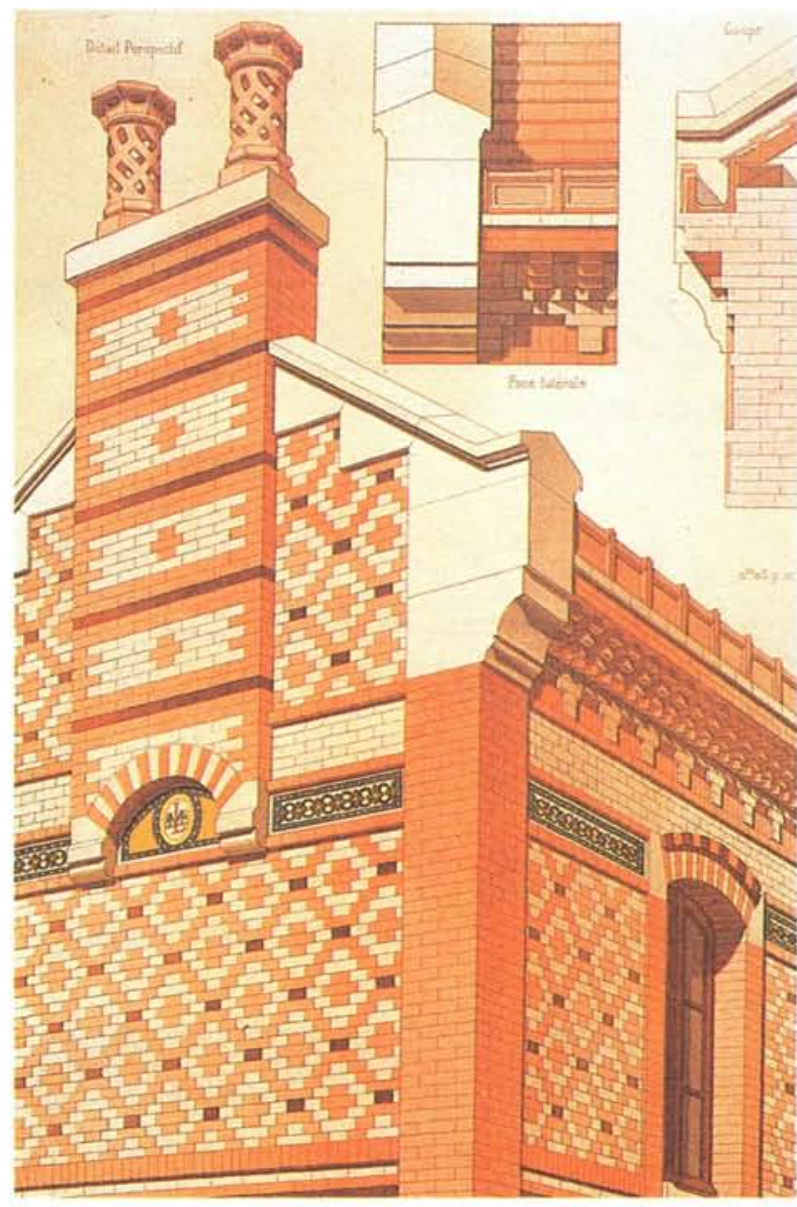

Fig. 4.-La Brique et la Terre Cuite, 1880 y 1889, Paris-P. Chabat. Casa para un Jardinero, aspectos constructivos y ornamentales del hastial.

Se encontrará arquitectura realizada en ladrillo visto, y con la misma racionalidad en el proceso constructivo, en puntos tan dispares como Londres o Milán, Berlín o Madrid. Incluso si pensamos en la Arquitectura americana, veremos cómo también esta influencia cruzó el Atlántico y se convirtió en una arquitectura de carácter popular, como lo reflejan algunos edificios de Memphis, de Chicago o la Plaza de Toros de Bogotá.

Las publicaciones de carácter gráfico realizadas en la época fueron un vehículo muy importante para la difusión de este modo de entender la arquitectura. Entre los libros más significativos está el Fleischinger, editado en Berlín en 1864 y reeditado más tarde en Barcelona en 1875, con el nombre de "Arquitectura de Ladrillos" (Fig. 5).

Estos tipos de libros eran principalmente una colección de láminas donde se expresaba la gramática del lenguaje del ladrillo ordenada por elementos. Describían de un modo simple la técnica constructiva de cada uno de ellos, y como punto final de estas combinaciones se daban modelos que el constructor podía reinterpretar de un modo directo. 


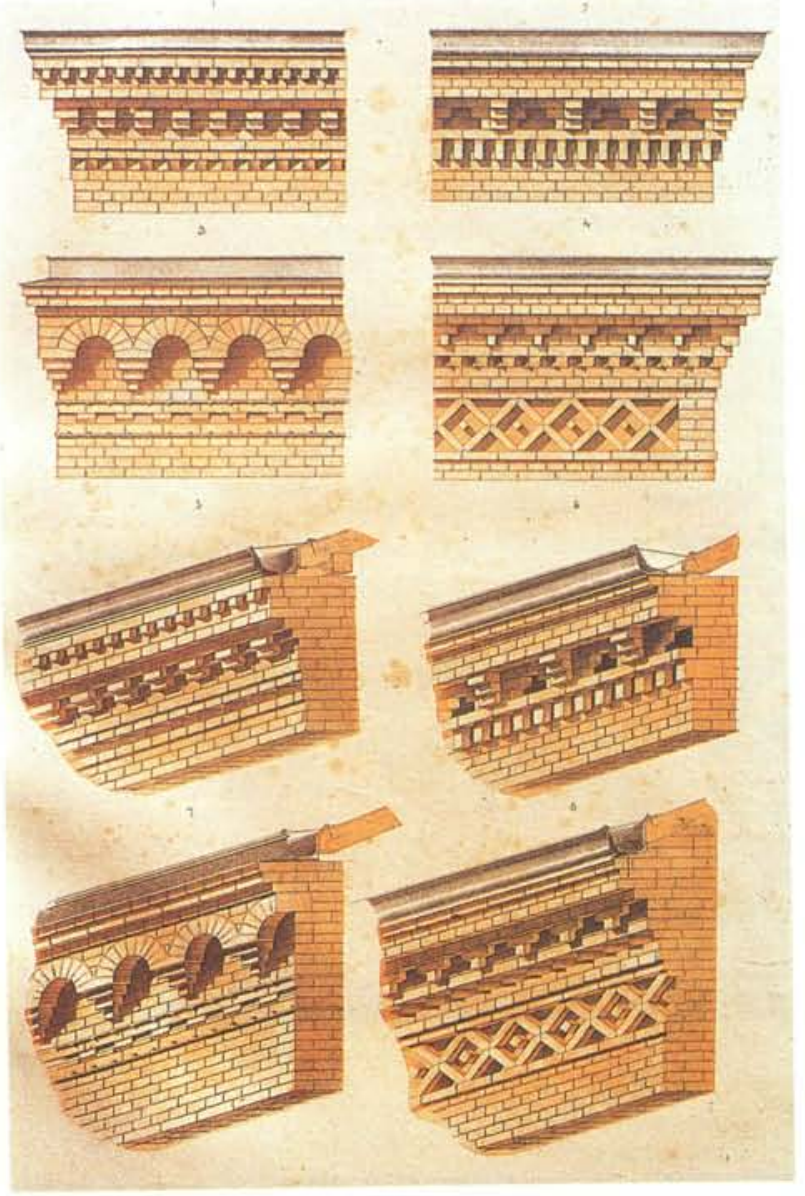

Fig. 5.-Arquitectura de Ladrillos, 1875, Barcelona-Fleischinger/Becker. Cornisas dibujadas en alzado y perspectiva seccionada para su total comprensión.

Las láminas de estas publicaciones, la mayoría de ellas impresas en color, avivaban la imaginación del artesanoalbañil, porque encontraba en ellas las reglas que le permitirían idear su propia creación.

\section{EL MURO RESISTENTE Y EL ARCO DE LADRILLO}

Respetando este juego racional de articulación de la pieza, junto a la libertad del albañil para expresar sus propios sentimientos contra la rigidez académica que suponía el clasicismo, tenemos que tener en cuenta otros condicionantes que hacen que una arquitectura con estilos tan diversos tenga, sin embargo, caracteres comunes, tanto desde el punto de vista formal como técnico.

Uno de ellos se refiere a las características resistentes de la fábrica de ladrillo; el otro, a la forma de abrir el hueco en este material.

La Arquitectura de Ladrillos se concibe normalmente con estructuras de muro de carga, sea cual sea la tipología del edificio, desde una iglesia o museo, hasta la vivienda más modesta.
La Arquitectura del siglo XIX plantea una homogeneización de la organización de la fábrica con una progresiva disminución de su grueso, gracias a la regularización de sus piezas y juntas, lo que permite apurar más sus cualidades resistentes a compresión del muro.

En las últimas décadas del XIX las estructuras de fundición se combinan con la fábrica resistente, independizándose progresivamente ambas, sobre todo en edificios industriales.

El carácter estructural del muro de carga decimonóni$\mathrm{co}$, va a influir en el diseño general del edificio. A nivel de fachadas, va a repercutir directamente en la composición de las mismas.

El grueso del muro, el ritmo macizo-hueco, la señalización formal de las líneas de impostas como líneas donde se apoyan los forjados, y de las cornisas como protección de la fachada del vuelo de la cubierta, se van a convertir en los temas destacados de ornamentación, confirmando con ello de nuevo la racionalidad y libertad de esta arquitectura.

En la ejecución de las cornisas se pone a prueba la capacidad resistente a flexión de la cerámica, al ir ganando vuelo sucesivo los elementos de la fábrica, sin incorporarse la capacidad a tracción del acero, lo que limita el vuelo de estos elementos apenas dos pies, en un máximo de 35 hiladas de altura en sucesivo salidizo (Figs. 6 y 7$)$.

De manera significativa se describe pormenorizadamente la apertura de huecos en la fábrica, como uno de los temas más característicos de esta arquitectura.

En la Arquitectura de Ladrillos, el proceso constructivo es aprovechado para explotar la expresividad del material, en un discurso técnico-formal basado en la técnica de ejecución de la fábrica.

El albañil experimenta con su libertad creativa, en una sucesiva combinación de "modillones", "dentellados" y "arpados", de amplitud y ritmo diverso, dotando de singularidad, originalidad y personalidad a cada obra.

Por el contrario podemos ver cómo razones formales, siguiendo tendencias estilísticas arquitectónicas, se imponen principalmente para determinar la forma de los $\operatorname{arcos}$ (Fig. 8). 

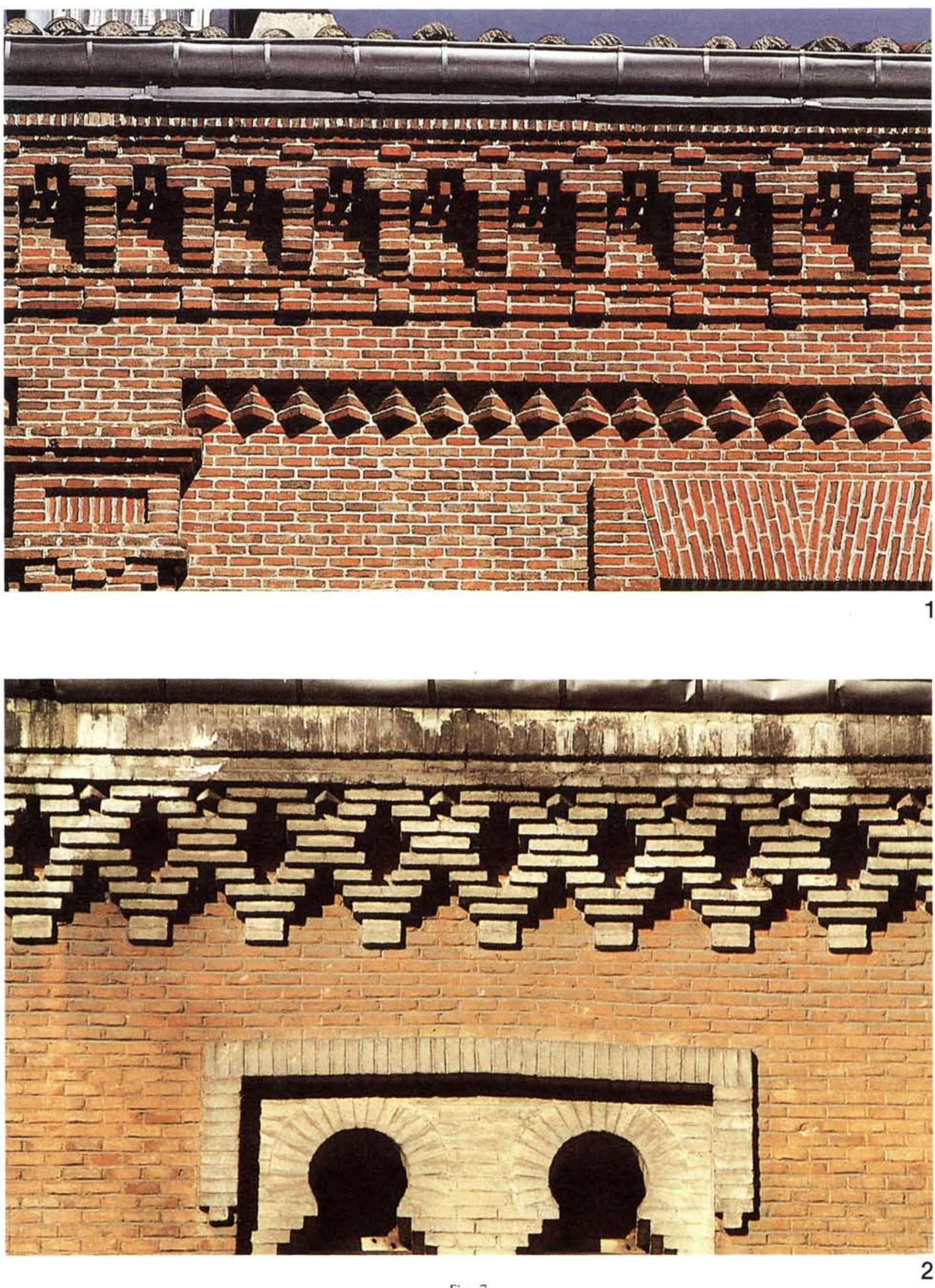

Fig. 7

1) Hospital de San José y de Santa Adela-J. Marañón/D. Zabala. Cornisa de dos cuerpos, el inferior arpado y el superior dentellado.

2) Convento de la Concepción Francisca (La Latina)-J. B. Lázaro. Cornisa dentellada en banda entrelazada de rombos de perfil escalonado en sucesivo vuelo. 
Escuelas Aguirre. Torre-E. Rodríguez Ayuso.

Cornisa de modillones a tizón cada pie y 13 hiladas, con motivo superior de hilada dentellada por tabla rehundida.

\section{I.C.A.I.-E. Fort}

Cornisa de tres cuerpos de 33 hiladas de altura y $13 / 4^{\prime}$ de vuelo con entrecalles molduradas de rombos resaltados:

a) Modillones a tizón cada pie.

b) Modillones de 1' cada 3' con rombo $(R 3+)(R I \bullet)$ en las entrecalles.

c) Bandas de hiladas a tizón resaltadas, voladas una de cada tres incluyendo la primera una hilada dentellada a sardinel rehundida.
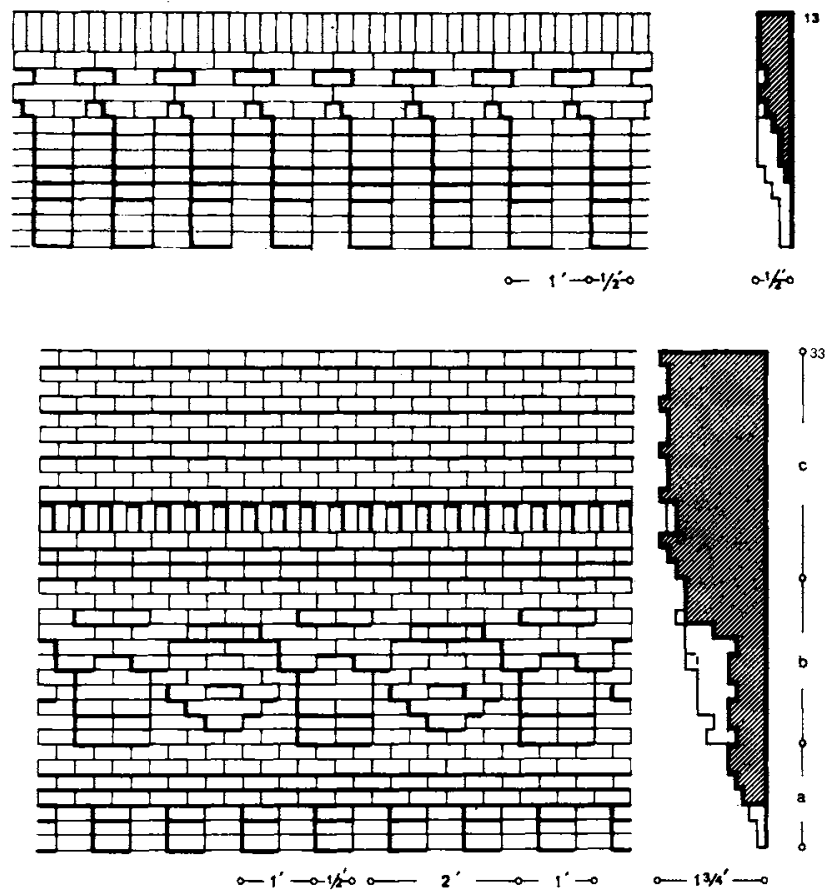

Fig. 6

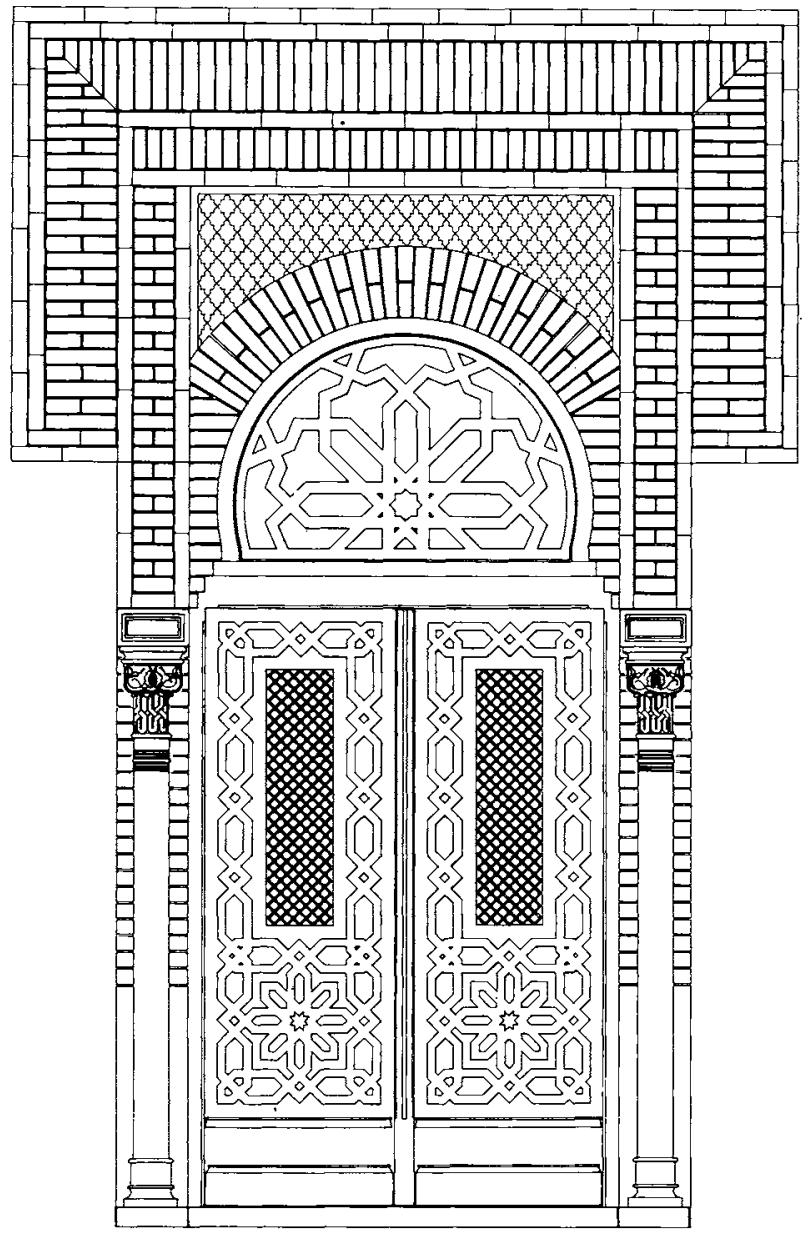

IIITIIIIITIIITI!
Instituto Valencia de D. Juán-E. Fort

Puerta de acceso bajo cubierto.

Arco de herradura con alfiz sobre pilares y capiteles granadinos. Puerta con lacerías.

- Arco de herradura aparejado de un pie de espesor con peralte de $r / 4$ que arranca sobre catorce hiladas horizontales, estando las cuatro primeras voladas sucesivamente, disponiéndose treinta y una dovelas de ladrillos acuñados, con tirantez al centro a partir del ángulo de $30^{\circ}$.

- Alfiz de hilada a sardinel encintada por hiladas a soga voladas, con realfiz de hilada a sardinel de canto encintada por dos hiladas a soga sucesivamente voladas.

- Enjutas tratadas con piezas cerámicas verdes, blancas y negras, hasta más arriba del trasdós del arco. El conjunto se ejecuta con ladrillo amarillo rojizo.

(c) Consejo Superior de Investigaciones Científicas Licencia Creative Commons 3.0 España (by-nc) http://informesdelaconstruccion.revistas.csic.es 


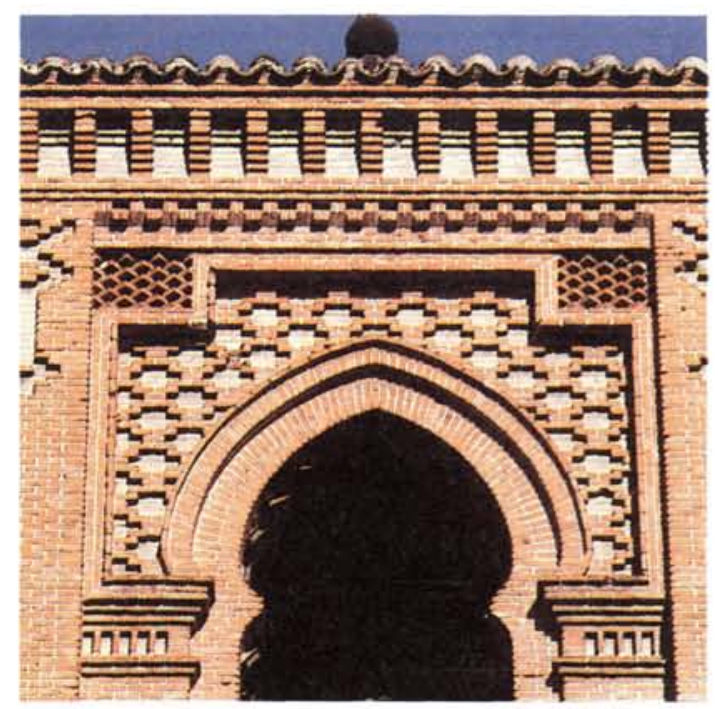

Iglesia de Santa Cristina-E. M. Repullés y Vargas. Arco de herradura lanceolado.

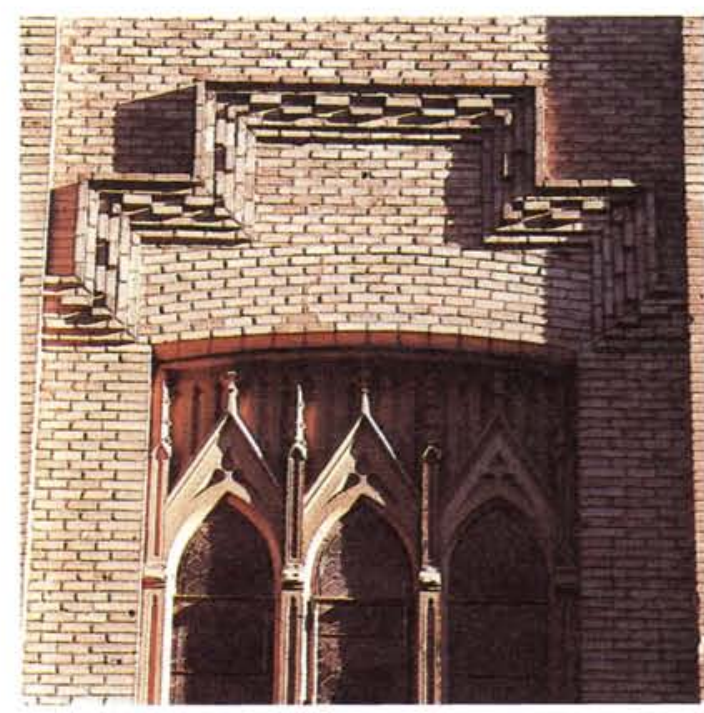

Asilo de San Diego y San Nicolás. J. B. Lázaro. Arco tabicado rebajado, bajo alfiz quebrado.

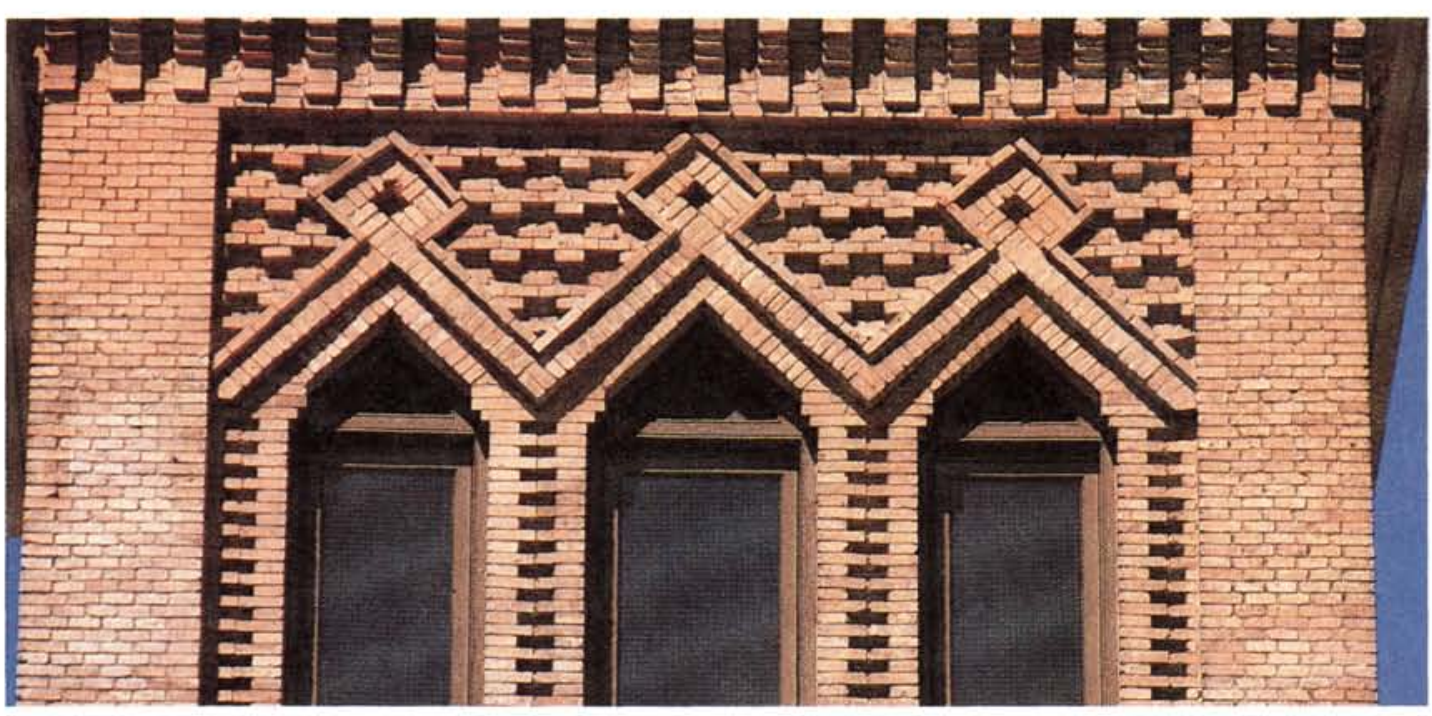

Escuelas Aguirre-E. Rodríguez Ayuso. Arcos agudos a $45^{\circ}$, en la trífora de la torre.

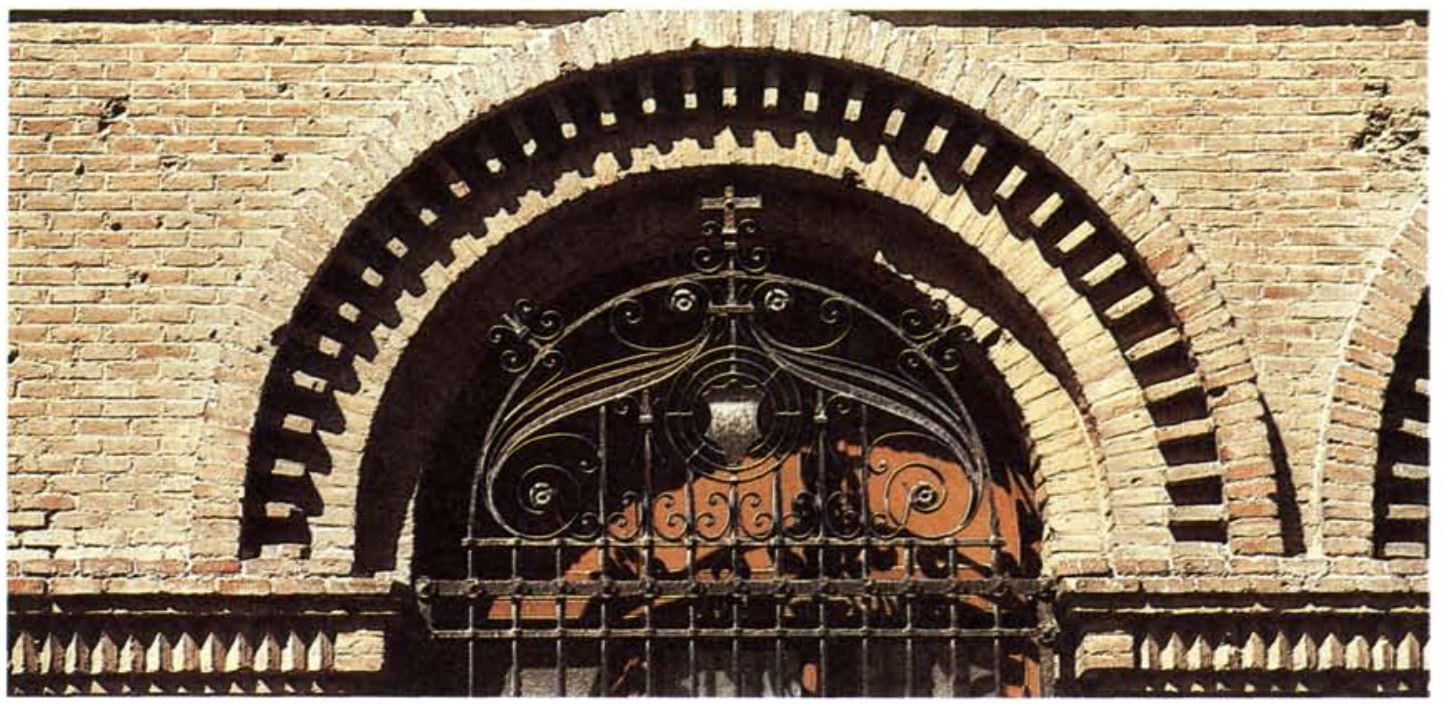

Seminario Conciliar-R. García Guereta/M. Olabarría. Arco de medio punto con arquivolta dentellada.

Fig. 9 
La solución estructural del cierre del muro es habitualmente la misma: el cierre en arco, que fuerza al trabajo a compresión del material de fábrica sobre el vano, y que permite a la hora de determinar su forma que se viertan todas las particularidades estilísticas que se han dado a nivel histórico o regional.

Se construye con una técnica de albañilería depurada, y se convierte la construcción del arco en un proceso de ornamentación en sí mismo, donde cada elemento: "roscas", "dovelas", "salmeres", "claves", “enjutas", "tímpanos"... son los motivos más importantes de la construcción y la composición del edificio.

En función del compromiso técnico-formal asumido encontraremos, atendiendo a su forma: arcos "rectilineos", "circulares", "compuestos" o "mixtos" y, dentro de estas formas, distintas organizaciones constructivas: "de roscas", "aparejados", "tabicados" o "de correa". Todo ello en su conjunto con tratamientos moldurados.

La riqueza expresiva del discurso técnico-formal expresado en el arco adquiere mayor amplitud por el hecho de poder plantear la gramática del ladrillo en varios planos, que van desde los "guardapolvos volados" del arco, hasta las "arquivoltas" que abocinan el hueco, pasando por el propio "frente" del arco en el haz del paramento (Fig. 9).

En todos los arcos merecen especial atención los tratamientos del arranque junto a "a los estribos" y del "cierre en la clave", ya sea con "dovela única" o constituida de varias piezas, "en espina de pez", "endentadas", "a bolsón", etc.

Las dovelas son objeto de esmerada ejecución acorde con la "tirantez" propia del arco, controlando la distribución del grueso variable de las juntas o "escopetas".

Es común hacer partícipe a las enjutas del arco sobre los "riñones" de algún motivo ornamental que recuadre el trasdós del arco, a modo de "alfiz".

La evolución experimentada en estos dos temas: el muro resistente y el arco, harán que la arquitectura posterior abandone estos repertorios formales, y estas técnicas constructivas, dando paso a nuevas técnicas y nuevos materiales, que dejarán de lado las posibilidades de evolución de las fábricas.
El primero porque se transforma en muro de cerramiento, comúnmente de hojas, cada vez más livianas, al deslindarse la estructura resistente de la obra de fábrica.

El segundo por la aparición de los cargaderos que sustituyen al arco con su capacidad de trabajo a flexión.

Entrado el siglo XX, el acero pasa decididamente a formar parte de la arquitectura; las estructuras de acero laminado y las de hormigón armado revolucionan la manera de construir; la capacidad a tracción de estos materiales consiguen cambiar la racional composición vertical impuesta por el ritmo entre huecos y macizos, arcos y estribos, por la horizontal en el tratamiento del hueco de la fábrica, una vez aliviada de compromisos resistentes.

Sólo ahora, casi entrando en el siglo XXI, nuevamente se retoman los valores de las fábricas, combinándose sabiamente el acero con el material de fábrica, potenciando sus cualidádes mediante la "fábrica armada".

Sin embargo, estos cambios no nos hacen olvidar nuestra admiración, con un punto de nostalgia, del trabajo realizado por tantos y tantos Arquitectos y Maestros Artesanos que volcaron su historia y su tiempo en una labor muchas veces anónima y poco valorada, buscando la máxima expresividad en la obra de fábrica de ladrillo, siguiendo las pautas de un elemento modular. Valga este artículo para rendirles homenaje.

\section{BIBLIOGRAFÍA}

(1) Arte de Albañilería. Juan de Vilanueva. Edición facsímil. Ediciones Velázquez. Madrid 1977. Original Madrid 1827.

(2) El Arte de Edificar. Manuel Fornés y Gurrea. Ediciones Poniente. Madrid 1982. El libro original está editado en 1846 y 1857.

(3) La Brique Ordinaire, au point de vue decoratif. Constructions en briques. J. Lacroux \& C. Detain. París 1878.

(4) Arquitectura de Ladrillos del siglo XIX. Técnica y forma. Josep $M^{a}$ Adell Argilés. Fundación Universidad Empresa Madrid 1985, 2. edición 1986.

(5) Sobre la denominación del "Aparejo a la Española". Josep $M^{a}$ Adell Argilés. Actas del I Congreso Hispanoamericano de Terminología de la Edificación. Valladolid 1987.

(6) Las Siete Lámparas de la Arquitectura. John Ruskin. Traducción Carmen de Burgos. F. Sempere. Ed. Valencia 1909. 